\title{
Impact of parental smoking on diabetes, hypertension and the metabolic syndrome in adult men and women in the San Antonio Heart Study
}

\author{
K. J. Hunt • A. Hansis-Diarte $•$ K. Shipman • \\ J. E. Korte • S. P. Fowler • M. P. Stern
}

Received: 23 March 2006 / Accepted: 7 June 2006 / Published online: 8 August 2006

(C) Springer-Verlag 2006

\begin{abstract}
Aims/hypothesis In the San Antonio Heart Study (SAHS) we investigated the effects of exposure to parental smoking on diabetes, hypertension and the metabolic syndrome in adult offspring aged 25-64 years.

Subjects, materials and methods In a retrospective cohort study the parental smoking status during childhood, obtained through a postal questionnaire, determined a person's exposure status. Logistic regression models were used to calculate odds ratios for diabetes, hypertension and the metabolic syndrome at the baseline SAHS examination in relation to parental smoking status. All models were adjusted for age, sex, ethnicity, education years, personal smoking status (current, former or never-smoker), BMI and, in the case of diabetes, a family history of diabetes.

Results Of the 2,371 participants who returned the mailing, $44.5,5.4,20.0$ and $30.1 \%$ reported that their father, mother, both or neither parent smoked, respectively. Participants reporting that both parents smoked were $1.60(95 \% \mathrm{CI}$ : $0.95-2.69)$ times more likely to have diabetes, 1.55 (95\% CI: $1.05-2.28)$ times more likely to have hypertension, and $1.46(95 \%$ CI: $1.01-2.10)$ times more likely to have the metabolic syndrome than participants reporting that neither parent smoked during their childhood. Odds ratios, after
\end{abstract}

K. J. Hunt $(\bowtie) \cdot$ J. E. Korte

Department of Biostatistics, Bioinformatics and Epidemiology, Medical University of South Carolina,

135 Cannon Street, Suite 303, P.O. Box 250835, Charleston, SC 29425, USA

e-mail: huntke@musc.edu

A. Hansis-Diarte $\cdot$ K. Shipman - S. P. Fowler • M. P. Stern Division of Clinical Epidemiology, Department of Medicine, University of Texas Health Science Center,

San Antonio, TX, USA limiting the population to younger participants (i.e. $\leq 50$ years) to reduce survivor bias, were $2.53(95 \% \mathrm{CI}$ : 1.21-5.31), 1.29 (95\% CI: $0.78-2.16)$, and 1.41 (95\% CI: 0.89-2.22) for diabetes, hypertension and the metabolic syndrome, respectively.

Conclusions/interpretation These results provide evidence that early exposure to parental smoking may be associated with an increased risk of diabetes and perhaps hypertension and the metabolic syndrome.

Keywords Diabetes · Epidemiology · Hypertension ·

Metabolic syndrome $\cdot$ Parental smoking $\cdot$ Pregnancy

\author{
Abbreviations \\ HBP High blood pressure \\ MetS $_{\text {NCEP }}$ National Cholesterol Education Program- \\ defined metabolic syndrome \\ SAHS San Antonio Heart Study
}

\section{Introduction}

Until recently, much of the research on diabetes, hypertension and the metabolic syndrome has focused on adult lifestyles, but it is now suspected that early life exposures may be important to the development of these metabolic diseases. Low birthweight has been associated with adult disorders such as type 2 diabetes, hypertension and coronary heart disease [1-14]. According to the 'foetal origin of adult diseases' hypothesis on which these studies have been based, reduced nutrition in utero leads to adaptive changes in the foetus $[15,16]$. These adaptive changes, called programming, help ensure the survival of 
the foetus but in an affluent environment after birth, they may have adverse effects leading to the development of obesity, type 2 diabetes and coronary heart disease $[15,16]$. Smoking during pregnancy is one of the main environmental causes of intrauterine growth retardation. Children of both active and passive smokers have lower weight and length and less fat mass at birth than children of nonsmokers [17-20]. Moreover, recent studies have reported an increased risk of obesity in the offspring of mothers who smoked during pregnancy [21-26], and a single study reported an increased risk of type 2 diabetes in the offspring of mothers who smoked during pregnancy [27].

Recently, we collected retrospective information on parental smoking status during early childhood from members of the San Antonio Heart Study (SAHS) cohort. Participants aged 25-64 years at their baseline examination were asked to report whether their mother, father, or both parents smoked when they were a young child. Using this information, our objective was to examine whether parental smoking during early childhood and perhaps pregnancy as well, increased the risk of type 2 diabetes, hypertension or the metabolic syndrome in adult offspring who participated in the SAHS.

\section{Subjects, materials and methods}

The SAHS design and population

The SAHS cohort consists of 5,158 participants, recruited at baseline in two phases: phase 1 between 1979 and 1982, and phase 2 between 1984 and 1988. Details of the study design have been published previously [28-30]. The Institutional Review Board of the University of Texas Health Science Center at San Antonio approved the study, and all subjects gave informed consent.

\section{Baseline SAHS cohort examination}

The baseline SAHS cohort examination was standardised and included interviews, blood pressure measurements, anthropometry, fasting blood analyses and an oral glucose tolerance test. Trained interviewers obtained information on demographic variables, medical history, medication use and smoking status.

Ethnicity was defined by a validated algorithm [28]. Socioeconomic status was assessed with the Duncan socioeconomic index, a global measure based on occupational prestige [31, 32], and by years of education. Participants were asked to fast for at least $12 \mathrm{~h}$ before their examination. Measurement of blood pressure, BMI, waist circumference, total and HDL cholesterol, triglycerides and plasma glucose and insulin (fasting and $2 \mathrm{~h}$ after a standardised 75 -g oral glucose load) has been previously described [30, 33].

Diabetes was defined as fasting plasma glucose $\geq 7.0 \mathrm{mmol} / 1 \mathrm{and} /$ or 2 -h postload glucose $\geq 11.1 \mathrm{mmol} / 1$ [34]. Participants not meeting these criteria but who reported current therapy with diabetes medication (either oral or insulin) were also considered to have diabetes. Hypertension was defined as systolic blood pressure $\geq 140 \mathrm{mmHg}$, diastolic blood pressure $\geq 90 \mathrm{mmHg}$, or current treatment with antihypertensive medication. Overweight was defined as a BMI $\geq 25 \mathrm{~kg} / \mathrm{m}^{2}$ and $<30 \mathrm{~kg} / \mathrm{m}^{2}$, and obesity was defined as a BMI $\geq 30 \mathrm{~kg} / \mathrm{m}^{2}$. The metabolic syndrome was defined according to the National Cholesterol Education ProgramAdult Treatment Panel III (ATPIII) criteria $\left(\mathrm{MetS}_{\mathrm{NCEP}}\right)$. MetS $_{\mathrm{NCEP}}$ was defined as having at least three of the following NCEP metabolic abnormalities [35]: fasting glucose $\geq 5.6 \mathrm{mmol} / \mathrm{l}$ or taking medication for diabetes [36], abdominal obesity (waist circumference $>102 \mathrm{~cm}$ in men, or $>88 \mathrm{~cm}$ in women), high blood pressure $(\geq 130 / \geq 85 \mathrm{mmHg}$ ) or taking medication for hypertension, triglycerides $\geq 1.7 \mathrm{mmol} / \mathrm{l}$, or low HDL cholesterol $(<1.1 \mathrm{mmol} / 1$ in men, $<1.4 \mathrm{mmol} / 1$ in women). Because waist circumference was not measured during the first phase of recruitment in the SAHS, the waist criterion for phase 1 participants (43\%; $n=1,009)$ was imputed using sex-specific logistic regression equations developed in phase 2 participants based on log-transformed weight, height and ethnicity. To validate our approach, we imputed waist circumference using the selected cut-points in follow-up data from phase 1 participants (1987-1990). Agreement between MetS $_{\mathrm{NCEP}}$-defined and imputed waist circumference criteria was high ( $\kappa$ statistic $=0.69,95 \%$ CI: $0.66-0.73$ ). Agreement between Met $\mathrm{S}_{\mathrm{NCEP}}$ values based on defined and imputed waist circumference criteria was very high ( s statistic $=0.91,95 \%$ CI: $0.89-0.93$ ).

Study population and retrospective collection of information

Of the 5,158 SAHS participants, 708 (13.7\%) were dead in 2002 when the mailing was sent and 2,371 returned the postal questionnaire which asked whether their father smoked, mother smoked, both parents smoked or neither parent smoked during their childhood. Hence, the study population for the current analysis is comprised of these 2,371 individuals with a response rate among survivors of $53.3 \%$. The parental smoking information collected retrospectively defined an individual's early life exposure status. Because many of the older SAHS participants had died by the time the retrospective questionnaire was completed, to reduce the potential for bias, a further analysis was completed limited to the 1,697 participants who were 50 years or younger at their baseline SAHS examination 
and who had completed the mailing. Of the 5,158 SAHS participants, $528(32.6 \%)$ of the 1,622 SAHS participants older than 50 years at their baseline examination had died by the time of the mailing, while only $180(5.1 \%)$ of the 3,536 participants aged 50 years or less at their baseline examination had died at the time of the mail-out. The response rate among survivors in the younger sub-cohort was $50.6 \%$.

\section{Statistical analyses}

A retrospective cohort analysis was carried out in which parental smoking status during an individual's childhood was used to define his or her own early life exposure status. The outcomes of interest were diabetes, hypertension and MetS $_{\text {NCEP. }}$ Two sets of analyses were completed: the first included all participants who completed the questionnaire $(n=2,371)$, while the second was limited to those participants 50 years or younger at their baseline SAHS examination $(n=1,697)$.

Age-, sex- and ethnicity-adjusted means and proportions were determined for participant characteristics stratified by parental smoking status (i.e. neither smoked, father smoked, mother smoked or both smoked). Analysis of covariance was used to generate adjusted means and logistic regression was used to generate adjusted proportions.

Separate logistic regression models were used to calculate odds ratios for diabetes, hypertension and $\mathrm{Met}_{\mathrm{NCEP}}$ in relation to parental smoking status. Three index variables were used to code the four levels of parental smoking status: neither parent smoked (reference category), only the father smoked, only the mother smoked, and both parents smoked. Covariates included in initial models for each outcome were age, sex and ethnicity. Additional covariates included in secondary and tertiary models for each outcome were years of education, personal smoking status (current, former, or never-smoker), BMI and, in the case of diabetes, a family history of diabetes. Furthermore, when an association was identified between parental smoking status and an outcome of interest, models with and without the appropriate interaction terms between parental smoking status and each covariate were compared in the younger sub-cohort (i.e. $\leq 50$ years) to identify interactions between parental smoking status and covariates in relation to that outcome: a global $p$ value of 0.05 across all interaction terms was used as a nominal value of statistically significant interaction.

\section{Results}

Of the 2,371 study participants who responded to the mailed questionnaire, $713(30.1 \%)$ reported that neither parent smoked during their childhood, 1,054 (44.5\%) reported that only their father smoked during their childhood, 129 (5.4\%) reported that only their mother smoked during their childhood, and 475 (20.0\%) reported that both of their parents smoked during their childhood.

Age-, sex- and ethnicity-adjusted means and proportions for participant characteristics stratified by parental smoking status during early childhood are displayed in Table 1 . Participants who reported that neither parent smoked during their childhood were slightly older and more likely to be Mexican American than participants who reported that both of their parents smoked during their childhood. Participants who reported that neither parent smoked were less likely to have diabetes, hypertension and $\mathrm{MetS}_{\mathrm{NCEP}}$ as adults than participants who reported that both parents smoked after adjusting for age, sex and ethnicity. Similarly, fasting glucose levels and BMI were higher in participants who reported that both parents smoked relative to the participants who reported that neither parent smoked after adjustment for age, sex and ethnicity. Total and HDL cholesterol levels were similar in individuals regardless of whether or not either or both of their parents smoked. Socioeconomic status measured by the Duncan socioeconomic index scale was lower when only the mother smoked than when neither parent smoked, while socioeconomic status measured by years of education was lower when both or either of the parents smoked than when neither parent smoked. Participants who reported that neither parent smoked were less likely to report a family history of diabetes than participants who reported that both parents smoked. Finally, participants who reported that both parents smoked were more likely to be current or former smokers than participants who reported that during their childhood neither parent smoked.

Moreover, because many of the participants were deceased (13.7\%) when the postal questionnaire was sent, we examined the prevalence of diabetes, hypertension and MetS $_{\text {NCEP }}$ in participants 50 years or younger at their baseline examination $(n=1,697)$. Within this younger subcohort only $5.1 \%$ were deceased at the time of the parental smoking questionnaire mailing (Fig. 1) As expected, the prevalence of diabetes, hypertension and $\mathrm{Met}_{\mathrm{NCEP}}$ was lower in this younger subset of the population. In this subset, after adjusting for age, sex and ethnicity, participants who reported that neither parent smoked were significantly less likely to have diabetes or $\mathrm{MetS}_{\mathrm{NCEP}}$ as an adult compared with those participants who reported that both parents smoked. Similarly, although not statistically significant, participants who reported that neither parent smoked were less likely to have hypertension as an adult compared with participants who reported that both parents smoked.

We examined the relationship between diabetes, hypertension and $\mathrm{MetS}_{\mathrm{NCEP}}$ and the four parental smoking status 
Table 1 Characteristics of the total study population stratified by parental smoking category adjusted for age, sex and ethnicity

\begin{tabular}{|c|c|c|c|c|c|}
\hline & \multicolumn{5}{|c|}{ Parental smoking status during early childhood } \\
\hline & $\begin{array}{l}\text { Neither smoked } \\
(n=713)\end{array}$ & $\begin{array}{l}\text { Only father } \\
(n=1,054)\end{array}$ & $\begin{array}{l}\text { Only mother } \\
(n=129)\end{array}$ & $\begin{array}{l}\text { Both smoked } \\
(n=475)\end{array}$ & $\begin{array}{l}F \text { statistic } \\
\text { or global } \mathrm{P}\end{array}$ \\
\hline Age (years) ${ }^{\mathrm{a}}$ & $45.0(44.3-45.8)$ & $44.3(43.7-44.9)$ & $43.7(41.9-45.4)$ & $40.2(39.2-41.1)^{* * *}$ & $<0.0001$ \\
\hline Male $(\%)^{\mathrm{a}}$ & $41.0(37.4-44.6)$ & $42.9(39.9-45.9)$ & $38.8(30.8-47.4)$ & $44.2(39.8-48.7)$ & 0.563 \\
\hline Mexican Americans $(\%)^{\mathrm{a}}$ & $61.7(58.1-65.2)$ & $51.8(48.8-54.8)^{* * *}$ & $65.9(57.3-73.5)$ & $45.1(40.6-49.6)^{* * *}$ & $<0.0001$ \\
\hline Diabetes $(\%)$ & $4.0(2.9-5.6)$ & $3.6(2.7-4.9)$ & $4.4(2.2-8.6)$ & $6.9(4.8-9.8)^{*}$ & 0.035 \\
\hline Hypertension (\%) & $9.0(7.2-11.3)$ & $11.9(10.0-14.1)^{*}$ & $11.4(7.1-17.9)$ & $13.5(10.5-17.1)^{*}$ & 0.084 \\
\hline MetS $_{\text {NCEP }}(\%)$ & $15.3(12.8-18.1)$ & $19.2(16.8-21.7)^{*}$ & $26.9(19.8-35.5)^{* *}$ & $22.5(18.7-26.9)^{* *}$ & 0.002 \\
\hline Fasting glucose $(\mathrm{mmol} / \mathrm{l})$ & $5.1(4.9-5.2)$ & $5.1(5.0-5.2)$ & $5.2(5.0-5.4)$ & $5.3(5.2-5.4)^{* *}$ & 0.011 \\
\hline 2-h glucose $(\mathrm{mmol} / \mathrm{l})$ & $6.3(6.1-6.5)$ & $6.3(6.1-6.4)$ & $6.8(6.3-7.3)$ & $6.7(6.4-6.9)$ & 0.024 \\
\hline BMI $\left(\mathrm{kg} / \mathrm{m}^{2}\right)$ & $26.3(26.0-26.7)$ & $26.9(26.6-27.2)^{*}$ & $27.4(26.6-28.3)^{*}$ & $27.3(26.8-27.8)^{* *}$ & 0.005 \\
\hline $\begin{array}{l}\text { Total cholesterol } \\
(\mathrm{mmol} / \mathrm{l})\end{array}$ & $5.2(5.2-5.3)$ & $5.2(5.2-5.3)$ & $5.3(5.1-5.5)$ & $5.3(5.2-5.4)$ & 0.789 \\
\hline $\begin{array}{l}\text { HDL cholesterol } \\
(\mathrm{mmol} / \mathrm{l})\end{array}$ & $1.4(1.3-1.4)$ & $1.3(1.3-1.4)$ & $1.3(1.3-1.4)$ & $1.3(1.3-1.4)$ & 0.366 \\
\hline Current smoker (\%) & $17.7(15.0-20.7)$ & $22.8(20.3-25.4)^{*}$ & $29.4(22.1-37.9)^{* *}$ & $26.0(22.2-30.2)^{* * *}$ & 0.001 \\
\hline Former smoker (\%) & $22.5(19.5-25.8)$ & $24.1(21.5-26.9)$ & $27.6(20.4-36.1)$ & $28.3(24.3-32.8)^{*}$ & 0.141 \\
\hline $\begin{array}{l}\text { Duncan SEI (scale: } \\
0-100)\end{array}$ & $58(56-59)$ & $56(55-58)$ & $53(50-57)^{*}$ & $57(55-59)$ & 0.119 \\
\hline Education (years) & $13.3(13.1-13.6)$ & $13.0(12.8-13.2)^{*}$ & $12.4(11.8-12.9)^{* *}$ & $12.9(12.6-13.2)^{*}$ & 0.004 \\
\hline $\begin{array}{l}\text { Diabetes family history } \\
(\%)\end{array}$ & $26.5(23.3-29.9)$ & $29.3(26.5-32.3)$ & $32.2(24.6-40.9)$ & $33.2(28.9-37.9)^{*}$ & 0.103 \\
\hline
\end{tabular}

Data are presented as percentages or means and 95\% confidence intervals. Pairwise comparisons are with the 'neither smoked' category $S E I$, Socioeconomic index

${ }^{*} p<0.05,{ }^{* *} p<0.01, * * * p<0.001$

${ }^{\mathrm{a}}$ Unadjusted

categories using those who reported that neither parent smoked during childhood as the referent group (Table 2). Initially, analyses were completed in the total population. Participants reporting that both parents smoked were 1.73 (95\% CI: 1.06-2.84) times more likely to have diabetes than participants reporting that neither parent smoked after adjusting for age, sex, ethnicity, years of education and personal smoking status (Model 2). Additional adjustment for BMI and a family history of diabetes attenuated the odds ratio only slightly $(\mathrm{OR}=1.60$ [95\% CI: 0.95-2.69]) (Model 3). Odds ratios comparing participants who reported that both parents smoked to participants who reported that neither parent smoked were 1.57 (95\% CI: 1.08-2.28) for hypertension and 1.55 (95\% CI: 1.13-2.13) for $\mathrm{MetS}_{\mathrm{NCEP}}$ after adjusting for age, sex, ethnicity, years of education and personal smoking status (Model 2). With additional adjustment for BMI the odds ratios for hypertension $\left(\mathrm{OR}=1.55\right.$ [95\% CI: 1.05-2.28]) and $\mathrm{MetS}_{\mathrm{NCEP}}$ $(\mathrm{OR}=1.46$ [95\% CI: 1.01-2.10]) were attenuated only slightly (Model 3).

We repeated these analyses in participants who were 50 years or younger at their baseline examination (Table 2).
In this subset of the population the association between parental smoking status and adult diabetes status was strengthened, while the association with hypertension was weakened somewhat and the association with MetS $\mathrm{S}_{\mathrm{NCEP}}$ was unchanged. The odds ratio comparing participants who reported that both parents smoked to participants who reported that neither parent smoked was 2.53 (95\% CI: 1.21-5.31) for diabetes after adjustment for all covariates including BMI and a family history of diabetes, and 1.29 (95\% CI: 0.78-2.16) for hypertension and 1.41 (95\% CI: 0.89-2.22) for $\mathrm{Met}_{\mathrm{NCEP}}$ after adjustment for all covariates including BMI. There was no evidence of significant interaction between parental smoking status and covariates for any of the outcomes of interest.

\section{Discussion}

In this retrospective cohort study, adult participants aged 50 years or less who reported that both parents had smoked during their childhood were 2.5 times more likely to have diabetes, independent of their own smoking status, com- 

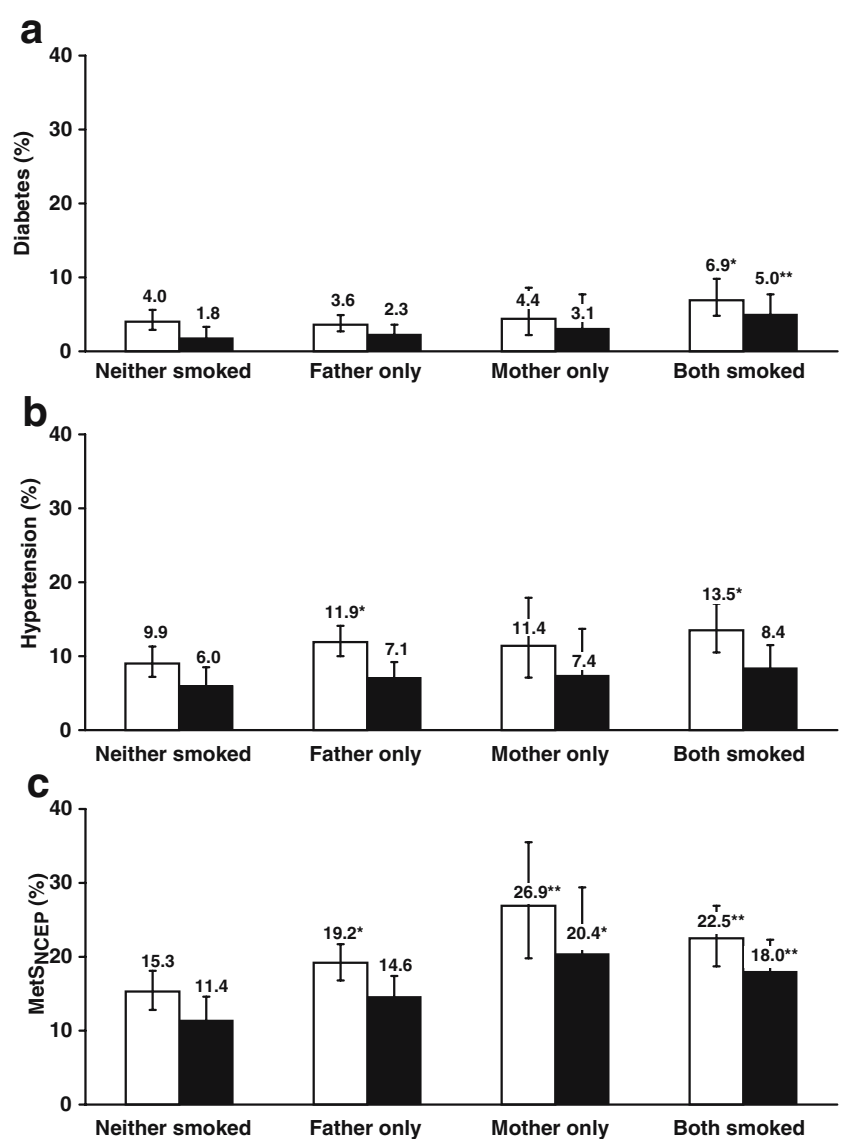

Fig. 1 Prevalence of diabetes (a), hypertension (b) and $\mathrm{MetS}_{\mathrm{NCEP}}(\mathbf{c})$ stratified by parental smoking category adjusted for age, sex and ethnicity in the total study population (empty bars) and in participants aged less than 50 years (filled bars). ${ }^{*} p<0.05,{ }^{*} p<0.01$ vs neither smoked category within each study population

pared with participants reporting that neither parent had smoked. Moreover there was some evidence of increased rates of hypertension and the metabolic syndrome among participants who reported that both parents smoked relative to those who reported that neither parent smoked. Traditionally, epidemiological studies of cardiovascular disease and its risk factors have focused on current or recent characteristics of adult study participants. However, early life exposures are emerging as potentially important risk factors. In the current study, we use parental smoking status during the respondent's childhood as a surrogate marker of parental smoking status while the participant was in utero.

The 'foetal origin of disease' hypothesis proposes that gestational programming may critically influence adult health and disease [37]. Gestational programming is a process whereby stimuli or stresses that occur at critical or sensitive periods of development permanently change structure, physiology and metabolism, hence predisposing individuals to disease in adult life [38]. Epidemiological studies of the Dutch famine at the end of World War II provide some evidence in support of the foetal origin of disease hypothesis [39, 40]. In an initial study, 19-year-old male conscripts who had previously been exposed to famine during the first two trimesters of their intrauterine development were at increased risk of obesity [40]. In a more recent study, 50-year-old women, but not men, who had been exposed to the Dutch famine in utero had increased BMI and waist circumference [39].

In the early 1990s Hales and Barker put forward the 'thrifty phenotype' hypothesis, which proposes that low birthweight, indicative of poor prenatal nutrition, has an effect on development that manifests itself later in life as an increased risk for a number of chronic diseases [1, 3, 37]. In support of the 'thrifty phenotype' hypothesis, studies of adults have identified an inverse association between birthweight and type 2 diabetes [1-6, 8], impaired glucose tolerance [1,6], elevated insulin levels [6], hypertension [7-11], and cardiovascular disease [12-14, 37]. Hence, although birthweight is a non-specific measure of foetal nutrition during pregnancy, it has been shown to be associated with adult disease.

Maternal smoking during pregnancy, as well as exposure to environmental tobacco smoke, is known to affect the intrauterine supply of nutrients and oxygen and is well known to result in lower birthweight babies; however, few studies have examined the relationship between intrauterine exposure to smoke and adult disease. A number of recent studies have reported an association between maternal smoking status during pregnancy and childhood obesity [20-27, 41]. The largest of these studies, a study of 8,500 German children aged 5-7 years, reported a $2.8 \%$ prevalence of obesity (defined as a BMI greater than the 97th percentile) in offspring of mothers who never smoked compared with a $6.2 \%$ prevalence of obesity in offspring of mothers who smoked throughout pregnancy [23]. We know of only a single study which has examined the association between maternal smoking during pregnancy and adult obesity [27]. This study of a British longitudinal birth cohort of over 11,000 participants aged 33 years, reported an odds ratio for obesity (defined as a BMI $\geq 30 \mathrm{~kg} / \mathrm{m}^{2}$ ) of 1.38 (95\% CI: 1.07-1.69) among participants whose mothers smoked heavily during pregnancy, compared with those with non-smoking mothers [27].

Even fewer studies have examined the association between maternal smoking status and hypertension or diabetes. A few studies have examined the association between maternal smoking during pregnancy and childhood blood pressure levels [41-43]. Results from these studies are inconsistent, with a study of 3,360 British children aged 5-7 years finding no association between maternal smoking and childhood blood pressure levels [43], but a prospective cohort study of 1,708 pregnant women and their singleton offspring reporting a positive association between maternal smoking status and increased systolic blood pressure at age 6 independent of birthweight [41]. Finally, the previously 
Table 2 Odds ratios (and 95\% confidence intervals) for the association between parental smoking status and adult diabetes, hypertension and MetS $_{\text {NCEP }}$ status

\begin{tabular}{|c|c|c|c|c|c|c|}
\hline & \multicolumn{2}{|l|}{ Diabetes status } & \multicolumn{2}{|c|}{ Hypertension status } & \multicolumn{2}{|l|}{ MetS $_{\text {NCEP }}$ status } \\
\hline & Total & $\leq 50$ years & Total & $\leq 50$ years & Total & $\leq 50$ years \\
\hline \multicolumn{7}{|l|}{ Model $1^{\mathrm{a}}$} \\
\hline Neither smoked & 1.00 & 1.00 & 1.00 & 1.00 & 1.00 & 1.00 \\
\hline Only father smoked & $0.89(0.59-1.34)$ & $1.24(0.63-2.45)$ & $1.36(1.02-1.81)$ & $1.19(0.77-1.82)$ & $1.32(1.02-1.69)$ & $1.33(0.94-1.86)$ \\
\hline Only mother smoked & $1.09(0.51-2.34)$ & $1.72(0.59-4.96)$ & $1.30(0.74-2.29)$ & $1.25(0.59-2.64)$ & $2.04(1.31-3.18)$ & $1.99(1.14-3.45)$ \\
\hline Both smoked & 1.77 (1.09-2.87) & $2.79(1.38-5.64)$ & $1.56(1.08-2.27)$ & $1.43(0.87-2.33)$ & $1.61(1.18-2.20)$ & $1.70(1.16-2.51)$ \\
\hline \multicolumn{7}{|l|}{ Model $2^{\mathrm{b}}$} \\
\hline Neither smoked & 1.00 & 1.00 & 1.00 & 1.00 & 1.00 & 1.00 \\
\hline Only father smoked & $0.88(0.58-1.34)$ & $1.26(0.64-2.51)$ & $1.35(1.01-1.81)$ & $1.18(0.76-1.81)$ & $1.30(1.01-1.67)$ & $1.35(0.95-1.89)$ \\
\hline Only mother smoked & $1.01(0.46-2.19)$ & $1.60(0.55-4.69)$ & $1.29(0.73-2.30)$ & $1.17(0.55-2.51)$ & $1.96(1.25-3.08)$ & $1.91(1.09-3.36)$ \\
\hline Both smoked & $1.73(1.06-2.84)$ & $2.79(1.37-5.67)$ & $1.57(1.08-2.28)$ & $1.40(0.85-2.29)$ & $1.55(1.13-2.13)$ & $1.66(1.12-2.45)$ \\
\hline \multicolumn{7}{|l|}{ Model $3^{\mathrm{c}}$} \\
\hline Neither smoked & 1.00 & 1.00 & 1.00 & 1.00 & 1.00 & 1.00 \\
\hline Only father smoked & $0.85(0.55-1.31)$ & $1.11(0.54-2.27)$ & $1.34(0.99-1.80)$ & $1.11(0.71-1.74)$ & $1.24(0.92-1.66)$ & $1.20(0.80-1.79)$ \\
\hline Only mother smoked & $0.96(0.43,2.12)$ & $1.47(0.48,4.49)$ & $1.24(0.69,2.22)$ & $1.05(0.48,2.29)$ & $1.88(1.10,3.22)$ & $1.59(0.80,3.15)$ \\
\hline Both smoked & $1.60(0.95,2.69)$ & $2.53(1.21,5.31)$ & $1.55(1.05,2.28)$ & $1.29(0.78,2.16)$ & $1.46(1.01,2.10)$ & $1.41(0.89,2.22)$ \\
\hline
\end{tabular}

${ }^{a}$ Model 1 is adjusted for age, sex and ethnicity (Mexican American, non-Hispanic white)

${ }^{\mathrm{b}}$ Model 2 is additionally adjusted for socioeconomic status as defined by years of education and personal smoking status (current, former, or never-smoker)

${ }^{\mathrm{c}}$ Model 3 is adjusted for the factors in Model 2, as well as BMI and, in the case of diabetes, family history of diabetes

mentioned British longitudinal birth cohort of 11,000 participants aged 33 years reported an odds ratio for diabetes of 4.6 (95\% CI: 1.8-11.4) comparing participants whose mothers smoked heavily during pregnancy with participants with non-smoking mothers [27].

There are several possible mechanisms that may explain our observed associations between parental smoking status during early childhood and the subsequent development of diabetes, the metabolic syndrome and possibly hypertension in adult offspring. Intrauterine exposure to both active and passive smoking is associated with low birthweight [17-20]; hence, low birthweight may mediate the association between exposure to cigarette smoke in utero and diabetes as an adult. Alternatively, is has been suggested that persistent effects of the intrauterine environment may be greatest on tissues that are almost completely developed and differentiated at birth, such as pancreas, muscle and adipose tissue. Interestingly, many of these tissues are likely to play a role in the development of diabetes and the metabolic syndrome. For instance, poor foetal growth has been associated with a reduced number of beta cells [44], and studies have indicated that individuals who are thin at birth are at increased risk of insulin resistance as adults [45, 46]. Finally, intrauterine exposure to cigarette smoke may affect hypothalamic appetite control centres either directly $[47,48]$ or indirectly as a result of undernutrition in utero $[49,50]$, and dysfunctional appetite control is likely to influence the energy imbalance that often precedes the development of the metabolic syndrome and diabetes.
While the majority of previous studies have examined the association between maternal smoking status during pregnancy and childhood obesity in the offspring, our intent was to examine the association between parental smoking status during early childhood and metabolic diseases in adult offspring. Moreover, our aim was to determine whether obesity in the offspring mediated or modified any observed associations between parental smoking status and metabolic diseases in adult offspring. Interestingly, adjusting for BMI attenuated the odds ratios of interest only slightly. For each metabolic disorder, comparing participants who reported that both parents smoked with those who reported that neither parent smoked, the odds ratios were attenuated by no more than $10 \%$ with one exception-for the metabolic syndrome in the younger sub-cohort the odds ratio was attenuated by $15 \%$. Additionally, we did not find evidence that obesity (defined as a BMI greater than or equal to $30 \mathrm{~kg} / \mathrm{m}^{2}$ ) modified the association between parental smoking status and adult metabolic disorders; however, we had limited power to detect such an interaction. Hence, our observed associations between parental smoking status and adult metabolic disorders appear relatively independent of obesity levels in the offspring.

A number of confounders, including a participant's personal smoking status and socioeconomic status, may contribute to the observed association between parental smoking status and metabolic disorders in adult offspring. Adjusting for these potential confounders attenuated the 
odds ratios of interest only slightly; however, we cannot rule out the possibility that residual confounding may have accounted for the observed associations. Familial environment is another confounder that may account for the observed associations. Familial environment during childhood is strongly associated with personal behaviour as an adult and parental smoking status is only one component of familial environment during childhood. For instance, the association between parental smoking status and metabolic disorders in adult offspring may be explained by an association between parental smoking status and poorer diet or less exercise during childhood, which is perpetuated in the lifestyle of the adult. However, if familial environment confounded the relationships of interest we would expect a participant's personal smoking status, socioeconomic status and BMI to significantly attenuate the odds ratios of interest. This was not the case in our analyses. Finally, information on a participant's birthweight would enable us to examine whether birthweight itself mediated the observed associations between parental smoking status and metabolic disorders as an adult. Unfortunately, information on birthweight was available for only a very small subset of participants for whom we had information on parental smoking status. However, in a previous publication of 582 SAHS participants, lower birthweight was associated with higher fasting insulin levels, greater truncal fat deposition and higher odds of having the insulin resistance syndrome [2].

Our study has a number of limitations. Adult participants were asked to recall whether or not their parents had smoked during the respondents' childhood. Hence, not only was information on parental smoking status collected retrospectively but parents' smoking status was reported by their offspring. Moreover, because few participants would have specific knowledge of whether their parents smoked while they were in utero, we asked about parental smoking status during the respondent's childhood, which is also likely to reflect in utero exposure. Because participants were born before the public health warnings about the dangers of smoking during pregnancy, between 1915 and 1962 , and because individuals usually start smoking at a young age we believe that parental smoking status is unlikely to have changed between a participant's time in utero and his or her childhood, especially when the smoking status of mother and father is concordant. Furthermore, any resulting misclassification is likely to be non-differential with respect to the child's disease status as an adult and would therefore bias the estimates of association towards the null. A second limitation of the study is that we do not have information available to quantify the level of parental smoking; hence, we are unable to examine dose response. A third limitation of our study is that we only have information on parental smoking on $46 \%$ of the original cohort, which may affect the generalisability of our study. In the total population men and women were equally likely to return the postal questionnaire, but Mexican Americans (39\%) were less likely to return it than non-Hispanic whites (59\%). Furthermore, participants who returned the mailing were of a similar age but had more years of education than participants who failed to return the mailing (13.7 vs 10.7 years of education). Finally, because the information on parental smoking status was collected years after the initiation of the SAHS, survival bias may be influencing our results. However, we have attempted to account for survival bias by limiting the study to participants aged 50 years or younger at their clinical examination.

In summary, our results provide evidence that in a population of Mexican Americans and non-Hispanic whites, the risk of diabetes, the metabolic syndrome and possibly hypertension may be influenced by early exposure to parental smoking. Additional research is required to determine the impact of early life exposures on adult disease.

Acknowledgments This study was supported by grants from the National Heart Lung and Blood Institution (R01-HL24799 and R01HL36820), the National Institute of Diabetes Digestive and Kidney Diseases (K01 Award, 1K01 DK064867) and the American Diabetes Association (Research Award, 7-03-RA-118).

Duality of interest There is no duality of interest to report.

\section{References}

1. Hales CN, Barker DJ, Clark PM et al (1991) Fetal and infant growth and impaired glucose tolerance at age 64. BMJ 303:1019-1022

2. Valdez R, Athens MA, Thompson GH, Bradshaw BS, Stern MP (1994) Birthweight and adult health outcomes in a biethnic population in the USA. Diabetologia 37:624-631

3. Hales CN, Barker DJ (1992) Type 2 (non-insulin-dependent) diabetes mellitus: the thrifty phenotype hypothesis. Diabetologia 35:595-601

4. McCance DR, Pettitt DJ, Hanson RL, Jacobsson LT, Knowler WC, Bennett PH (1994) Birth weight and non-insulin dependent diabetes: thrifty genotype, thrifty phenotype, or surviving small baby genotype? BMJ 308:942-945

5. Rich-Edwards JW, Colditz GA, Stampfer MJ et al (1999) Birthweight and the risk for type 2 diabetes mellitus in adult women. Ann Intern Med 130:278-284

6. Robinson S, Walton RJ, Clark PM, Barker DJ, Hales CN, Osmond C (1992) The relation of fetal growth to plasma glucose in young men. Diabetologia 35:444-446

7. Curhan GC, Chertow GM, Willett WC et al (1996) Birth weight and adult hypertension and obesity in women. Circulation 94:1310-1315

8. Curhan GC, Willett WC, Rimm EB, Spiegelman D, Ascherio AL, Stampfer MJ (1996) Birth weight and adult hypertension, diabetes mellitus, and obesity in US men. Circulation 94:3246-3250

9. Barker DJ, Osmond C, Golding J, Kuh D, Wadsworth ME (1989) Growth in utero, blood pressure in childhood and adult life, and mortality from cardiovascular disease. BMJ 298:564-567 
10. Barker DJ, Bull AR, Osmond C, Simmonds SJ (1990) Fetal and placental size and risk of hypertension in adult life. BMJ 301:259-262

11. Law CM, de Swiet M, Osmond C et al (1993) Initiation of hypertension in utero and its amplification throughout life. BMJ 306:24-27

12. Rich-Edwards JW, Stampfer MJ, Manson JE et al (1997) Birth weight and risk of cardiovascular disease in a cohort of women followed up since 1976. BMJ 315:396-400

13. Osmond C, Barker DJ, Winter PD, Fall CH, Simmonds SJ (1993) Early growth and death from cardiovascular disease in women. BMJ 307:1519-1524

14. Fall CH, Vijayakumar M, Barker DJ, Osmond C, Duggleby S (1995) Weight in infancy and prevalence of coronary heart disease in adult life. BMJ 310:17-19

15. Hales CN, Barker DJ (2001) The thrifty phenotype hypothesis Br Med Bull 60:5-20

16. Godfrey KM, Barker DJ (2000) Fetal nutrition and adult disease. Am J Clin Nutr 71:1344S-1352S

17. WHO (1999) International consultation on environmental tobacco smoke (ETS) and child health. WHO/NCD/TFI/99.10.2005. WHO, Geneva, Switzerland

18. Donald JM, Hooper K, Hopenhayn-Rich C (1991) Reproductive and developmental toxicity of toluene: a review. Environ Health Perspect 94:237-244

19. Longo LD (1977) The biological effects of carbon monoxide on the pregnant woman, fetus, and newborn infant. Am J Obstet Gynecol 129:69-103

20. Zaren B, Lindmark G, Gebre-Medhin M (1996) Maternal smoking and body composition of the newborn. Acta Paediatr $85: 213-219$

21. Sowan NA, Stember ML (2000) Parental risk factors for infant obesity. MCN Am J Matern Child Nurs 25:234-240

22. Toschke AM, Montgomery SM, Pfeiffer U, von Kries R (2003) Early intrauterine exposure to tobacco-inhaled products and obesity. Am J Epidemiol 158:1068-1074

23. Toschke M, Koletzko B, Slikker W Jr, Hermann M, Von Kries R (2002) Childhood obesity is associated with maternal smoking in pregnancy. Eur J Pediatr 161:445-448

24. Vik T, Jacobsen G, Vatten L, Bakketeig LS (1996) Pre- and postnatal growth in children of women who smoked in pregnancy. Early Hum Dev 45:245-255

25. von Kries R, Toschke AM, Koletzko B, Slikker W Jr (2002) Maternal smoking during pregnancy and childhood obesity. Am J Epidemiol 156:954-961

26. Wideroe M, Vik T, Jacobsen G, Bakketeig LS (2003) Does maternal smoking during pregnancy cause childhood overweight? Paediatr Perinat Epidemiol 17:171-179

27. Montgomery SM, Ekbom A (2002) Smoking during pregnancy and diabetes mellitus in a British longitudinal birth cohort. BMJ 324:26-27

28. Hazuda HP, Comeaux PJ, Stern MP, Haffner SM, Eifler CW, Rosenthal M (1986) A comparison of three indicators for identifying Mexican Americans in epidemiologic research. Methodological findings from the San Antonio Heart Study. Am J Epidemiol 123:96-112

29. Mitchell BD, Hazuda HP, Haffner SM, Patterson JK, Stern MP (1991) Myocardial infarction in Mexican-Americans and nonHispanic whites. The San Antonio Heart Study. Circulation 83:45-51

30. Stern MP, Rosenthal M, Haffner SM, Hazuda HP, Franco LJ (1984) Sex difference in the effects of sociocultural status on diabetes and cardiovascular risk factors in Mexican Americans. The San Antonio Heart Study. Am J Epidemiol 120:834-851

31. Socioeconomic Factors Working Group (1985) In: Ostfeld AM, Eaker ED (eds) Measuring psychosocial variables in epidemio- logic studies of cardiovascular disease: Proceedings of a workshop. NIH publication series no. 85-2270. NIH, Bethesda

32. Duncan OD (1961) A socioeconomic index for all occupations. In: Reiss AJ Jr (ed) Occupations and social status. Free Press, Glencoe, New York, pp 109-258

33. Haffner SM, Stern MP, Hazuda HP, Rosenthal M, Knapp JA (1986) The role of behavioral variables and fat patterning in explaining ethnic differences in serum lipids and lipoproteins. Am J Epidemiol 123:830-839

34. Alwan A, King H (eds) (1999) Report of a WHO Consultation. Definition, diagnosis and classification of diabetes mellitus and its complications. Part 1. Diagnosis and classification of diabetes mellitus. Geneva, World Health Organization, Department of Noncommunicable Disease Surveillance, pp 1-59

35. Expert Panel on Detection, Evaluation, and Treatment of High Blood Cholesterol In Adults (2001) Executive Summary of The Third Report of The National Cholesterol Education Program (NCEP) Expert Panel on Detection, Evaluation, and Treatment of High Blood Cholesterol In Adults (Adult Treatment Panel III). JAMA 285:2486-2497

36. Grundy SM, Brewer HB Jr, Cleeman JI, Smith SC Jr, Lenfant C (2004) Definition of metabolic syndrome: report of the National Heart, Lung, and Blood Institute/American Heart Association conference on scientific issues related to definition. Circulation 109:433-438

37. Barker DJ (1995) Fetal origins of coronary heart disease. BMJ 311:171-174

38. Lucas A (1991) Programming by early nutrition in man. In: Bock GR, Whelan J (eds) The childhood environment and adult disease. Wiley, Chichester, UK, pp 38-55

39. Ravelli AC, van der Meulen JH, Osmond C, Barker DJ, Bleker OP (1999) Obesity at the age of $50 \mathrm{y}$ in men and women exposed to famine prenatally. Am J Clin Nutr 70:811-816

40. Ravelli GP, Stein ZA, Susser MW (1976) Obesity in young men after famine exposure in utero and early infancy. N Engl J Med 295:349-353

41. Williams S, Poulton R (1999) Twins and maternal smoking: ordeals for the fetal origins hypothesis? A cohort study. BMJ 318:897-900

42. Blake KV, Gurrin LC, Evans SF et al (2000) Maternal cigarette smoking during pregnancy, low birth weight and subsequent blood pressure in early childhood. Early Hum Dev 57:137-147

43. Whincup PH, Cook DG, Papacosta O (1992) Do maternal and intrauterine factors influence blood pressure in childhood? Arch Dis Child 67:1423-1429

44. Phillips DI, Hirst S, Clark PM, Hales CN, Osmond C (1994) Fetal growth and insulin secretion in adult life. Diabetologia 37:592-596

45. Phillips DI, Barker DJ, Hales CN, Hirst S, Osmond C (1994) Thinness at birth and insulin resistance in adult life. Diabetologia $37: 150-154$

46. Phillips DI (1996) Insulin resistance as a programmed response to fetal undernutrition. Diabetologia 39:1119-1122

47. Levin BE, Routh VH (1996) Role of the brain in energy balance and obesity. Am J Physiol 271:R491-R500

48. Levin ED, Wilkerson A, Jones JP, Christopher NC, Briggs SJ (1996) Prenatal nicotine effects on memory in rats: pharmacological and behavioral challenges. Brain Res Dev Brain Res 97:207-215

49. Plagemann A, Harder T, Melchior K, Rake A, Rohde W, Dorner G (1999) Elevation of hypothalamic neuropeptide Yneurons in adult offspring of diabetic mother rats. Neuroreport 10:3211-3216

50. Pighetti M, Tommaselli GA, D'Elia A et al (2003) Maternal serum and umbilical cord blood leptin concentrations with fetal growth restriction. Obstet Gynecol 102:535-543 